\title{
Paper Electrophoretic Studies on the Diastatic Enzymes of Molds
}

\section{Part I. Electrophoretic Technique and the Behaviours of Diastatic Enzymes Observed on Papers.}

\author{
By Tadahiko ANDo and Yōnosuke IKEDA* \\ The Scientific Research Institute, Bunkyo-ku, Tohyo
}

Received June 25, 1955

\begin{abstract}
A detailed procedure for the separation of diastatic enzymes of molds was established, which was based on their electrophoretic behaviours on a paper strip. For the detection of enzymes, a bioautographical method was newly devised. Comparing the enzymatic images appeared on the paper strip, the authors classified mold enzyme systems into five types.
\end{abstract}

In Japan and other Asian countries, various kinds of molds such as Aspergillus, Penicillium, Rhizopus, and Mucor are known to be valuable converting agents for the preparation of foods and wines from grains and potatoes. Among numerous reports concerning the mold enzyme system, the following two reports are outstanding owing to their systematic studies. According to Kitahara ${ }^{1)}$, who investigated the diastatic enzyme systems of molds by using iodine color reaction and saccharifying activity against soluble starch as the assay methods, these molds might be classified into six types in respect to their enzymatic composition, in contrast to Okazaki's view2) who classified the mold enzyme systems into five types by using different strains and another biometric technique.

The experiments which are reported here and the following one were carried out with the same idea as those referred to above, but in a different way to elucidate the actual composition of mold

* Present address; The Instirute of Applied Microbiology, University of Tokyo, Bunkyokw. Tokyo.

1) K. Kitahara M. Kurushima, J. Ferm Tecb. Japan 27 $1,44,182,213,254(1949), 28106,388,422$ (1950).

2) H. Okazaki, J. Agr. Chem. Suc. Japan, 24, 88 (1950). enzyme systems by making them visible on a filter paper.

\section{Methods}

Preparation of Enzyme Solution-The following twelve kinds of mold were studied in this experiment,

Aspergillus oryzae (0-8-1), Asp. sojae (0-13-8), Asp. glaucus (A-1-8), Asp. usamii (1-1 R150635), Asp. niger (A-9-9), Asp. awamori ( $\mathrm{K}-$ $20913)$, Asp. inati (6911), Rhizopus tonkinensis (R-6-4), Rh. javanicus, Rh. péka (IR-2-4), Penicillium chrysogenum (Q-174), Mucor spinescens ( $\mathrm{Mu}-3)$

The wheat-bran, inoculated with the mold and incubated at $30^{\circ}$ for 4 days, was extracted for 15-17 hours with 3 parts of distilled water in the presence of toluene. The enzyme fraction was precipitated from the filtrate by adding absolute alcohol to the final concentration of $75 \%$. The precipitate thus obtained was washed with absolute alcohol and dried in a vacuum-desiccator.

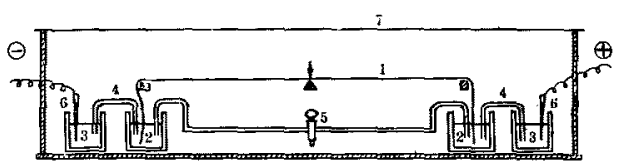

1, filter paper strip ; 2 , buffer vessel ; 3 carbon electrode vessel; 4, $1 \mathrm{M} \mathrm{KCl}-3 \%$ agar bridge; 5 , cock; 6, carbon electrode; 7 , glass cover.

Fig. 1. Apparatus employed for Electrophoretic Purpose. 


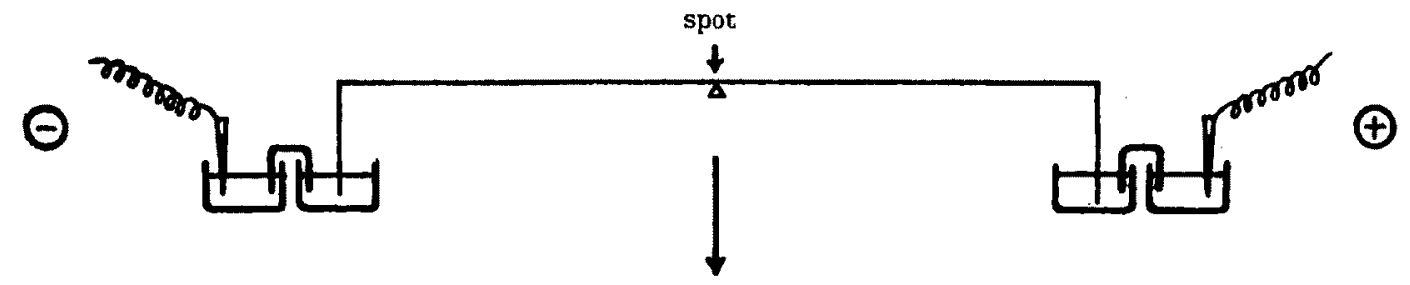

The finished paper strip

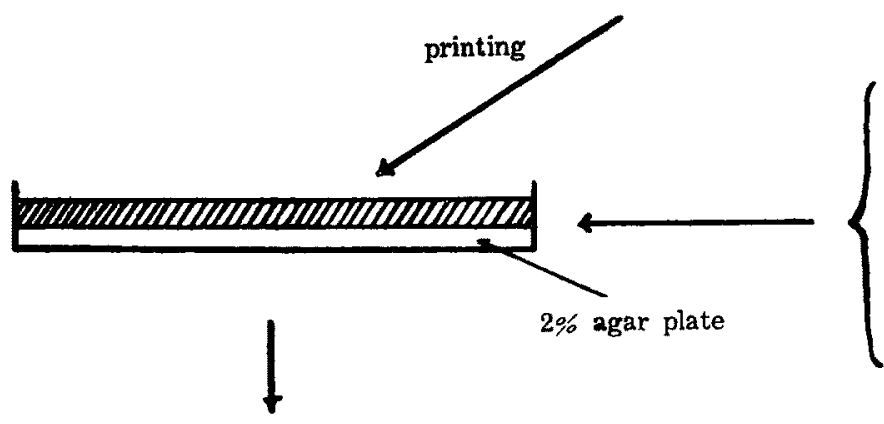

(1) For the purpose of detecting saccharogenic amylase, starch agar plates suspended with $S$. cerevisiae were employed.

(2) For the purpose of detecting maltase, maltose agar plates suspended with $S$. precisus were employed.

incubation for $2 \mathrm{hrs}$. at $30^{\circ} \mathrm{C}$

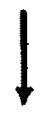

printed agar

\section{|IIIIIIIIIIII}

incubation for $20 \mathrm{hrs}$. at $30^{\circ} \mathrm{C}$

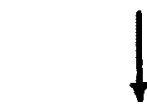

detection of the yeast

growing spots

(Bioautography)

Fig. 2. Bioautographic Technique. the removed paper strip

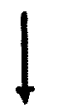

drying at $110^{\circ} \mathrm{C}$
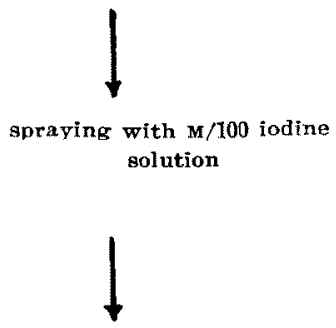

detection it the colorless s $\mu_{1}, \mathrm{~s}$ llodine reaction method, 
Vol. 19, No. 4, 1955] Paper Electrophoretic Studies on the Diastatic Enzymes of Molds

About $0.01 \mathrm{ml}$. aliquot of the enzyme solution was used in the electrophoretic experiment.

Electrophoresis-The apparatus employed in this experiment is shown in Fig. 1. The buffer vessels and the carbon electrode vessels were connected by means of $\mathrm{KCl}$-agar bridges to keep the paper clean from electrode products. By operating the apparatus at the potential gradient of $10 \mathrm{~V}$ per $\mathrm{cm}$, satisfactory results were obtained. The strips of paper (Toyo filter paper No. 50), wetted with $0.05 \mathrm{M}$ phosphate buffer and blotted on a dry filter paper to remove any excess moisture, were assembled to the apparatus. When equilibrium reached after thirty minutes, 0.01 $0.03 \mathrm{ml}$. aliquots of the sample were spotted on the starting line of strips, and electromigration was carried out for five hours at room temperature.

Detection of the Enzyme Locus-Two methods were employed for this purpose. The first, rely- ing on the iodine-starch reaction, served for the detection of dextrinogenic amylase* and the other, relying on bioautographic procedure and being devised by the authors, served for the detection of saccharogenic amylase* and maltase*.

For the detection of saccharogenic amylase, the paper strip was placed on the surface of a thin layer of $2 \%$ starch agar plate (medium-D) in which the cells of Saccharomyces cerevisiae Rasse Il had been previously suspended. After two hours contact, the paper strip was removed. The agar plate thus printed was placed again in an incubator for twenty hours at $30^{\circ}$. (see Fig. 2) During this period, the enzymatic reaction proceeded and the places corresponding to enzyme activities were made visible by the growth of yeast only on saccharified portions of the agar plate. On the whole, it was difficult for us to

* Further definition of these amylases will bo given in the following paper.

Table I

Composition of the Media tested for Bioautography.

\begin{tabular}{|c|c|c|c|c|c|}
\hline \multirow[b]{2}{*}{ Constituent } & \multicolumn{5}{|c|}{ Medium } \\
\hline & A & B & C & $\mathrm{D}$ & $\mathrm{E}$ \\
\hline Asparagine & & & $0.25 \%$ & & \\
\hline Peptone & & & & $0.5 \%$ & $1.0 \%$ \\
\hline $\begin{array}{l}\text { Beef ext. } \\
\mathrm{NH}_{4} \mathrm{H}_{2} \mathrm{PO}_{4}\end{array}$ & & $0.2 \%$ & & & $1.0 \%$ \\
\hline $\mathbf{K}_{2} \mathrm{HPO}_{4}$ & $0.5 \%$ & & $0.1 \%$ & & \\
\hline $\mathrm{KH}_{2} \mathrm{PO}_{4}$ & & $0.2 \%$ & & $0.5 \%$ & \\
\hline $\mathrm{MgSO}_{4} 7 \mathrm{H}_{2} \mathrm{O}$ & $0.2 \%$ & $0.2 \%$ & $0.3 \%$ & $0.2 \%$ & \\
\hline $\mathrm{NaCl}$ & & & & & $0.5 \%$ \\
\hline
\end{tabular}

Soluble starch (as in Table II.) and agar (2\%) were supplemented to the individual medium named A E.

Table II

Selection of Suitable Medium for the Detection of Saccharogenic Amylase.

\begin{tabular}{cccccc} 
Medium & $\begin{array}{c}\text { Time } \\
\text { (hours) }\end{array}$ & \multicolumn{2}{c}{ Concentration of Soluble Starch } & Remark \\
A & 20 & - & $1 \%$ & $2 \%$ & Rene \\
B & 20 & - & + & + & \\
C & 20 & - & + & ++ & \\
D & 20 & - & +++ & ++++ & suitable \\
E & 20 & - & +++ & ++++ & contamination
\end{tabular}

The growth rate of Sacbaromyces cere isiae Rasse II on these agar plate were recorded, using Taka-diastase as a converting agent. 
Table III

Selection of Suitable Test-organism for the Detection of Maltase.

Test-organism
Zygosacch. sp. No. 1
Zygosacch. sake var $\mathbf{K}$
Torulopsis sp. No. 28
Sacch. presisus

Growth on the agar plate

$\begin{array}{cc}20 \text { hrs. } & 40 \text { hrs. } \\ + & +++ \\ ++ & +++ \\ + & ++ \\ +++ & +++\end{array}$

Medium D supplemented with maltose $(2 \%)$ and agar $(2 \%)$ was used in this experiment.

detect saccharogenic amylases on a paper strip by the iodine-reaction, but this difficulty was easily overcome by the employment of bioautographic technique, the identification of enzymes being extremely simplified. The compositions of starch agar medium and other related media are shown in Tables I and II.

For the detection of dextrinogenic amylase, the paper strip removed from the agar plate was dried at $110^{\circ}$ for five minutes, and then sprayed with $0.01 \mathrm{~N}$ iodine solution. The position of dextrinogenic amylase was indicated as a well-defined clear spot depending on the reaction product.

For the detection of maltase, another bioautographic technique was employed. In this case, maltose was added to the medium $D$ instead of soluble starch, and Sacch. presisus was employed as test-organism in place of Sacch. cerevisiae Rasse II. As shown in Table III, Sacch. presisus proved to be the most suitable among these five strains tested, because it showed good growth on the medium only after the added maltose was converted to glucose by maltase.

\section{Results}

Electrophoretic Behaviors of D $x$ trinogenic Amylases-Electromigration was carried out at room temperature for five hours in $0.05 \mathrm{~m}$ phosphate buffer ( $\mathrm{pH} 7.6$ ) at the potential of 300 D.C. volts and at the current of $0.3 \mathrm{~m}$. amp $/ \mathrm{cm}$. Fig. 3 shows the colored zones of dextrinogenic amylases which appeared on paper strips treated with iodine solution. In contrast to the fact that the spots corresponding to the dextrinogenic amylases of $A s p$. oryzae $(+41 \mathrm{~mm})$, Asp. sojae (+41 mm),
Asp, glaucus ( $+40 \mathrm{~mm})$, Asp. usamii (+39 $\mathrm{mm})$, Asp. awamori $(+41 \mathrm{~mm})$, Asp. inui $(+40 \mathrm{~mm})$, Rh. péka $(+41 \mathrm{~mm}), M$. spinescens $(+39 \mathrm{~mm})$, and Pen. chrysogenum $(+41 \mathrm{~mm})$ were detected on the anode side with or without tailing effect, those of $R h$. tonkinensis $(-18 \mathrm{~mm})$ and $R h$. jnvanicus $(-18 \mathrm{~mm})$ were found on the cathode side.

Electrophoretic Behaviors of Saccharogenic Amylases-Electromigration was carried out in the same condition as mentioned above, and the bioautographic technique using Sacch. cerevisiae Resse II as the test-organism was employed in this experiment. As shown in Fig. 4, saccharogenic amylases of Asp. oryzae and Asp. sojae moved towards the anode side ( $+12 \mathrm{~mm}$ and $12 \mathrm{~mm}$ ) although with lower mobilities than the dextrinogenic amylases of those molds. So far as Asp. usamii is concerned, three spots were detected on the anode side $(+60 \mathrm{~mm},+37 \mathrm{~mm}$, $+24 \mathrm{~mm})$, among which two $(+60 \mathrm{~mm}$ and $24 \mathrm{~mm}$ ) were saccharogenic amylases without dextrinogenic activity and one $(+37 \mathrm{~mm})$ was the mixture of the two enzymes. One component each of the saccharogenic amylases of $A s p$. awamori and $A s p$. inui moved independently from their dextrinogenic amylases towards the anode $(+22 \mathrm{~mm})$. But the spots corresponding to saccharogenic amylases of $R h$. tonkinensis $(-40 \mathrm{~mm}), R h$. javanicus $(-40 \mathrm{~mm}), R h$. péka $(-12 \mathrm{~mm}), M$. spinescens $(-14 \mathrm{~mm})$, 
Vol. 19, No. 4, 1955] Paper Electrophoretic Studies on the Diastatic En:zymes of Molds

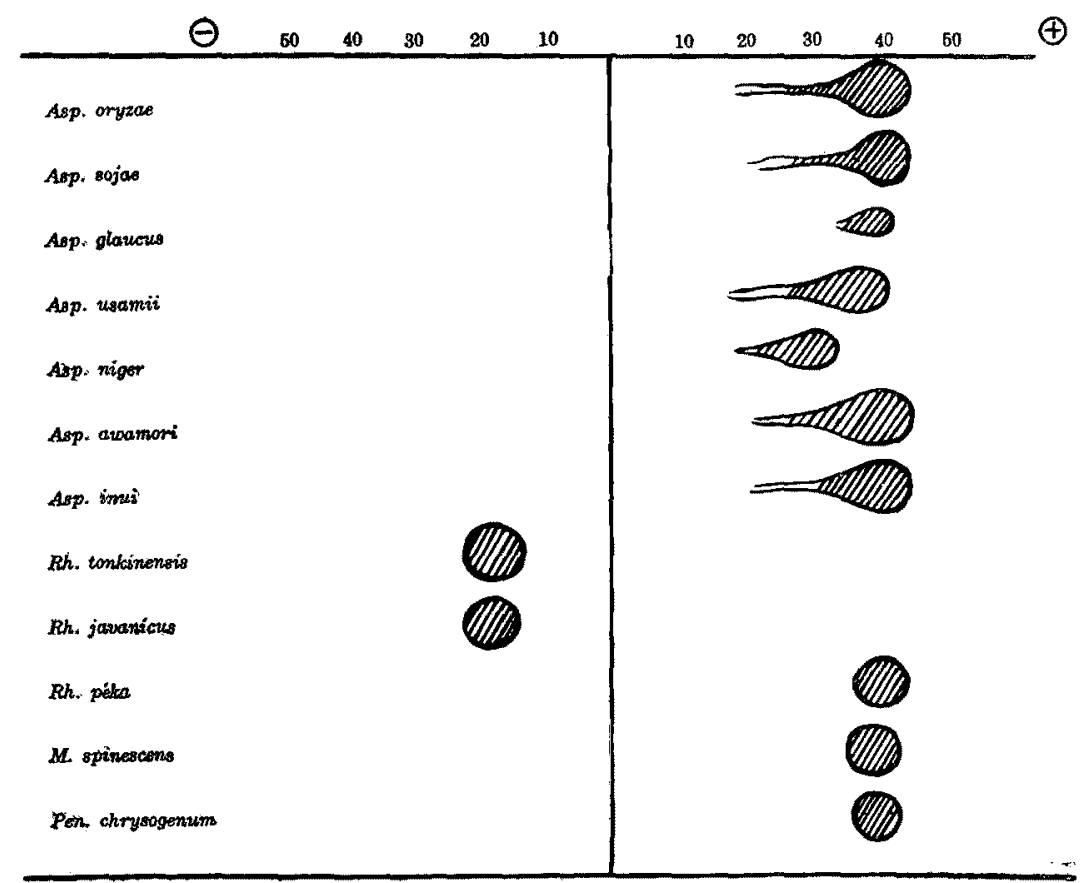

I ig. 3. Electrophoretic Behaviours of Dextrinogenic Amylases (detected by iodine-starch reaction).

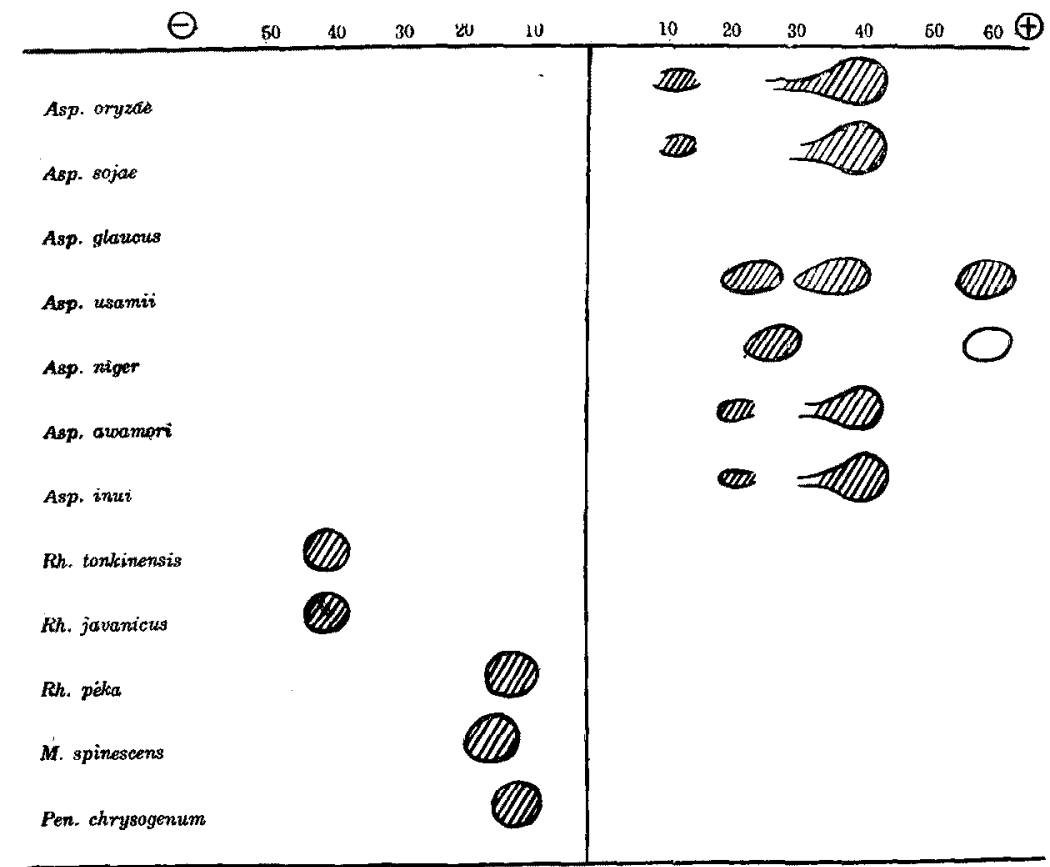

Fig. 4. Electrophoretic Behaviours of Saccharogenic Amylases (detected by bioautography). 


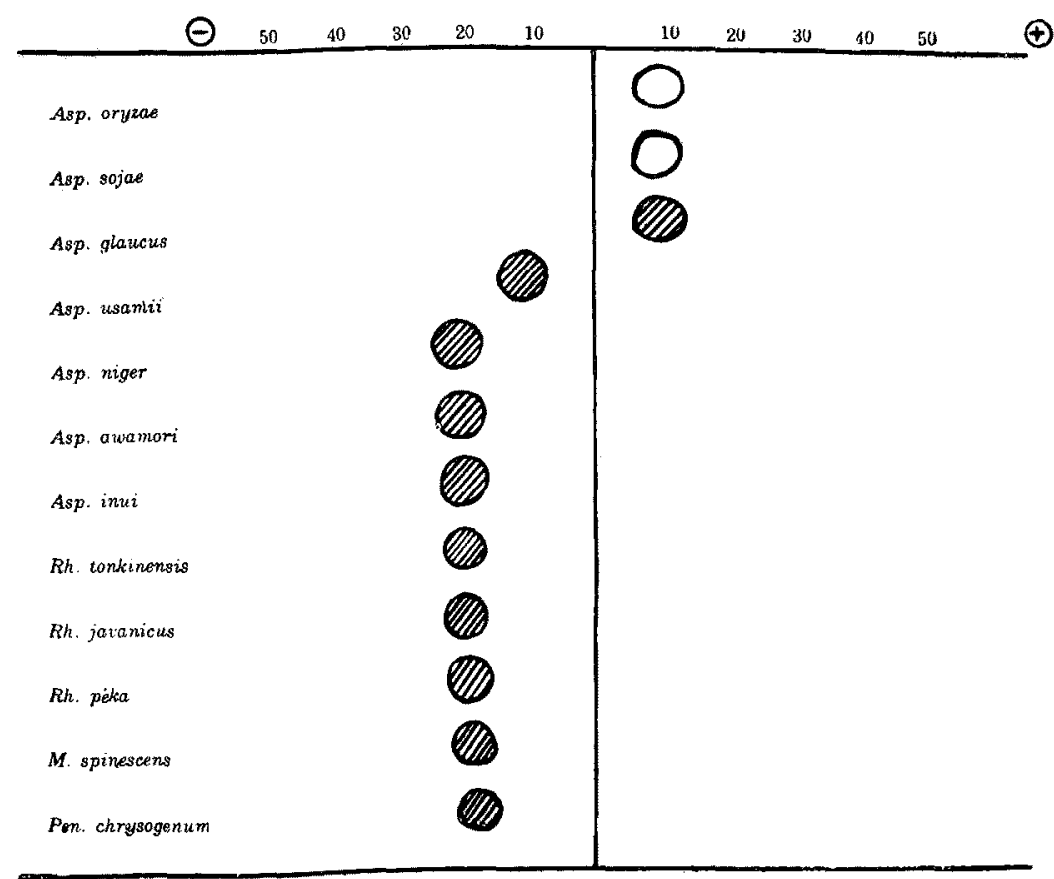

Fig. 5. Electrophoretic Behaviours of Maltases (detected by bioautography).

and Pen. chrysogenum (-11mm) were found on the cathode side. (see Fig. 4)

Electrophoretic Behaviors of Maltases-The spots corresponding to maltase of Asp. oryzae, Asp. sojae, and Asp. glaucus were found on the anode side considerably apart from the starting line. On the contrary, the maltase spots of the other strains were discovered on the cathode side $(-12 \sim-18 \mathrm{~mm}$ ). (see Fig. 5)

Effects of Heat-treatment on Enzyme Action-Following the description given by Okazaki, the enzyme solutions were treated at $\mathrm{pH} 2.5$ and at $40^{\circ}$ for thirty minutes. The results are summarized in Table IV.

\section{Discussion}

The data presented in this paper may be in favor of the following view, in which the mold enzyme systems were classified into five types from enzymologic point of view. (see Table IV)

Asp. oryzae type-All of the detected amylases, e.g. dextrinogenic amylase (non-resistant against the heat-treatment), saccharogenic amylase (resistant), and maltase (resistant) showed the tendencies to move towards the anode when they were analysed electrophoretically. The enzyme systems of $A s p$. sojae and $A s p$. glaucus may be classified in this type.

Asp.usamii type-Three spots of amylases were found on the anode side, among which two of them $(+60 \mathrm{~mm}$ and $+24 \mathrm{~mm})$ may be resistant sacchrogenic amylases, and the other one $(+37 \mathrm{~mm})$ a less resistant dextrinogenic amylases. The maltase of this type of mold was definitely characterized by its migration towards the cathode.

Asp. awamori type-The dextrinogenic amylase (resistant) and the saccharogenic amylase (resistant) migrated towards the 
Table IV

Classification of Molds by their Enzymatic Constitution.

Comppsition of Enzyme System

\begin{tabular}{|c|c|c|c|c|c|}
\hline Typical Strain & & & & $\begin{array}{l}\text { Mobility } \\
(\mathrm{pH} \mathrm{7.6)}\end{array}$ & $\begin{array}{c}\text { Homologous } \\
\text { Strains }\end{array}$ \\
\hline Asp. oryzae & $\left\{\begin{array}{l}(1) \\
(2) \\
(3)\end{array}\right.$ & $\begin{array}{l}(+) \text { type, non-res., } \\
(+) \text { type, res., } \\
(+) \text { type, res., }\end{array}$ & $\begin{array}{l}\text { D. A. } \\
\text { S. A. } \\
\text { M. }\end{array}$ & $\begin{array}{l}+2.9 \\
+0.8 \\
+0.6\end{array}$ & $\begin{array}{l}\text { Asp. oryzae } \\
\text { Asp. sojae } \\
\text { Asp. glaucus }\end{array}$ \\
\hline Asp. usamii & $\left\{\begin{array}{l}(1) \\
(2) \\
(3) \\
(4)\end{array}\right.$ & $\begin{array}{l}(+) \text { type, res., } \\
(+) \text { type, poorly res., } \\
(+) \text { type, res., } \\
(-) \text { type, res., }\end{array}$ & $\begin{array}{l}\text { S. A. } \\
\text { D.A. } \\
\text { S. A. } \\
\text { M. }\end{array}$ & $\begin{array}{l}+4.2 \\
+2.9 \\
+1.7 \\
-0.8\end{array}$ & Asp. usamii \\
\hline Asp. awamori & $\left\{\begin{array}{l}(1) \\
(2) \\
(3)\end{array}\right.$ & $\begin{array}{l}(+) \text { type, poorly res., } \\
(+) \text { type, res., } \\
(-) \text { type, res., }\end{array}$ & $\begin{array}{l}\text { D. A. } \\
\text { S. A. } \\
\text { M. }\end{array}$ & $\begin{array}{l}+2.9 \\
+1.6 \\
-1.4\end{array}$ & $\begin{array}{l}\text { Asp. awamori } \\
\text { Asp. imui }\end{array}$ \\
\hline$R h$. tonkinensis & $\left\{\begin{array}{l}(1) \\
(2) \\
3)\end{array}\right.$ & $\begin{array}{l}(-) \text { type, non-res., } \\
\text { (-) type, res., } \\
\text { type, res., }\end{array}$ & $\begin{array}{l}\text { D. A. } \\
\text { M. } \\
\text { S. A. }\end{array}$ & $\begin{array}{l}-1.2 \\
-1.3 \\
-2.8\end{array}$ & $\begin{array}{l}\text { Rh. tonkinensis } \\
\text { Rh. javanicus }\end{array}$ \\
\hline M. spinescens & $\left\{\begin{array}{l}(1) \\
(2) \\
(3)\end{array}\right.$ & 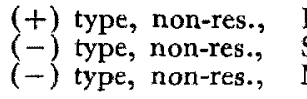 & $\begin{array}{l}\text { D. A. } \\
\text { S. A. } \\
\text { M. }\end{array}$ & $\begin{array}{l}+2.8 \\
-0.8 \\
-1.3\end{array}$ & $\begin{array}{l}\text { M. spinescens } \\
\text { Rh. péka } \\
\text { Pen. chrysogenum }\end{array}$ \\
\hline
\end{tabular}

\begin{tabular}{|c|c|}
\hline \\
\hline & \\
\hline$(-)$ type & migrated towards cathode side \\
\hline non-res. . & - non-resistant against the treatment \\
\hline & resistant against the treatment \\
\hline 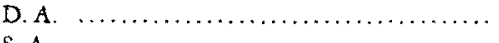 & dextrinogenic amylase \\
\hline 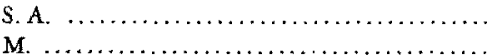 & saccharogenic amylase \\
\hline 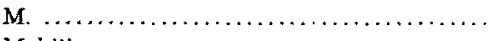 & malrase \\
\hline 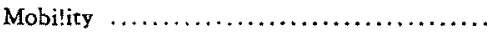 & $\mathrm{cm} / \mathrm{V} \cdot \mathrm{Sec}$ \\
\hline
\end{tabular}

anode side, in contrast to maltase (resistant) which migrated towards the cathode side. The enzyme system of $A s p$. inui may belong to this type.

$R h$. tonkinensis-All of the three spots migrated towards the cathode side. The dextrinogenic amylase was non-resistant, but saccharogenic amylase and maltase were resistant against the treatment. $R h$. javanicus may be one member of this type.

$M$. spinescens type-The dextrinogenic amylase migrated towards the anode side. The saccharogenic amylase and maltase of this type appeared on the cathode side, not so far from the startng line. All of them were non-resistant. $R h$. peka and Pen. chrysogenum may be of this type.

It is very interesting that the classifica- tion presented here shows very good agreement with those of Kitahara and Okazaki in spite of the fact that these three classifications were based on different methods. And the authors believe this work should be evaluated from the view point that the various kinds of diastatic enzyme of molds were successfully separated and became visible on a filter paper.

\section{Acknowledgment}

We wish to thank Prof. K. Sakaguchi and Dr. S. Iida for their valuable advice. The test-organisms used in this investigation were kindly supplied from the Institute of Applied Microbiology, University of Tokyo. 